\title{
FORMAÇÃO DE REGIÕES TRANSFRONTEIRIÇAS NA AMÉRICA DO SUL: UM ESTUDO COMPARADO DE CADEIAS PRODUTIVAS EM ESPAÇOS TRINACIONAIS
}

\author{
Gisela Pires do Rio; Maria Celia Nunes Coelho \\ Universidade Federal do Rio de Janeiro
}

\section{Resumo}

A formação de regiões transfronteiriças, objeto do presente artigo, tomou por base a noção de cadeia produtiva para elaborar uma análise comparada de duas áreas nas quais identificou-se processos de implantação e expansão de determinadas cadeias que estão na origem de uma dinâmica regional transfronteiriça, iniciada nos últimos 30 anos. A hipótese deste trabalho é a de que cadeias produtivas territorializadas impõem articulação espacial concreta em diferentes níveis, cotidiano, econômico e institucional. Duas áreas em tríplice fronteira foram selecionadas para comparação em corte sincrônico: Brasil-Paraguai-Argentina, em trecho da bacia do rio Paraná, e Brasil-Peru-Bolívia em trecho dos rios Acre, Madeira e Madre de Dios. A comparação entre essas áreas indicou uma região transfronteiriça em consolidação no Sul, enquanto no Norte a situação analisada indica o início do processo de formação de uma região seguindo um modelo similar.

Palavras-chave: organização regional, regiões transfronteiriças, integração regional, cadeias produtivas, redes técnicas, América do Sul.

\begin{abstract}
This article brings about the characterization and the comparison of the process of the differentiation of space in two cross-border regions in South America, one in Amazon basin and other in Prata basin. More specifically, in Brazil-Peru-Bolivia cross-border and the Brazil-Argentina - Paraguay border. We argued that cross-border regions have been developed by expanding of productive chain (extractive chain, pastoral and agricultural chain, innovation chain, and service chain). That means that the productive chain is an analytical and empiric tool to understand the emergence of such regions in the last 30 years. We conclude by regions have emerged particular because of the similar model of development of chains lagged in time.
\end{abstract}

Key words: regional organization, cross-border regions; regional integration, productive chain; techinical networks; South America. 


\section{Introdução}

A noção de fronteira talvez seja uma das mais exploradas na geografia e cuja evolução da história social do termo ao longo dos anos foi marcada por várias acepções. Mais recentemente, essa discussão ganhou projeção à medida em que avançava o processo de globalização e seu corolário, os inúmeros fins decretados ou estimados - "fim do território", "fim da história"... O fim das fronteiras também foi anunciado e a imagem de um "mundo sem fronteiras" encontrou grande receptividade, seja por sua associação à liberdade de circulação de mercadorias, indivíduos, informação e capitais, decorrente do próprio processo de globalização, seja pela ênfase à proximidade relacional e à diluição das distâncias viabilizadas pela tecnologia digital de comunicação. No entanto, nas duas primeiras décadas do século $\mathrm{XXI}$, as discussões parecem apontar para processos que reforçam o papel das fronteiras nas relações internacionais, seja como limite, como recurso, ou como elemento de integração negociada e de desenvolvimento regional.

Há, todavia, na própria evolução da globalização, uma tensão entre a retomada das fronteiras como temática relevante, por um lado, e a dinâmica econômica que impulsiona a formação de regiões transfronteiriças, amplia a escala para a elaboração de estratégias político-econômicas, ao mesmo tempo que favorece o aumento dos fluxos comerciais transfronteiriços. É nessa tensão que se reafirmam, os princípios de soberania e segurança (em seis aspectos: hídrica, energética, alimentar, pública, sanitária e de biodiversidade), e de integração regional supranacional. Entende-se por globalização o período histórico de intensificação do processo material de produção, distribuição e consumo, organizado por cadeias produtivas, cuja circulação depende de redes de infraestrutura viárias associadas às de comunicação. São essas redes de infraestrutura que configuram o espaço de fluxos.

A criação do Mercosul em $1994^{1}$ e as iniciativas de integração regional impulsionaram um conjunto significativo de investimentos em infraestrutura, principalmente no que diz respeito à integração dos respectivos sistemas energéticos, assim como ampliaram dinâmicas transfronteiriças propiciadas pela expansão de cadeias produtivas vinculadas à produção de proteína animal e vegetal, ao turismo e à extração de produtos florestais. Para compreender as peculiaridades do processo de formação de regiões transfronteiriças na América do Sul, adotou-se a premissa de que a expansão de determinadas cadeias produtivas presentes no continente está criando regiões transfronteiriças. Esta articulação pode ser mais ou menos evidente em função do nível de especialização, de complementaridade, de densidade de população e de atividades econômicas associadas a diferentes cadeias produtivas, e ao nível de inserção globalizada de cada cadeia considerada.

A temática sobre a formação de regiões transfronteiriças reafirma a fronteira como questão geoinstitucional, isto é, inscrita nas diferentes formas de regulação, normas do direito internacional, definidas por negociações, acordos e tratados internacionais, e balizadas pelos respectivos sistemas jurídicos e cambiais, e também pela

${ }^{1}$ O Tratado de Assunção assinado por Brasil, Argentina, Uruguai e Paraguai, em março de 1991, marcou oficialmente a criação do Mercosul, projeto de União aduaneira que teve seu início marcado para 31 de dezembro de 1994. Deve-se lembrar que as negociações para aprofundar a integração econômica iniciaram ainda na segunda metade da década de 1980. 
força das interações e trocas materiais locais e regionais. A análise sobre as fronteiras requer atribuir um sentido ao qualificativo transfronteiriço. Algumas premissas permanecem no terreno da obviedade, mas não por isso são menos importantes. A primeira premissa consiste no reconhecimento de que a estrutura internacional permanece organizada por unidades espaciais soberanas (Estados), redes técnicas e cadeias produtivas. A segunda refere-se à importância dos aglomerados urbanos como polos de dinâmica regional. A disponibilidade de redes de infraestrutura permite e orienta os fluxos vinculados à produção, transporte e distribuição de mercadorias, assim como os fluxos de indivíduos e de informação. Pela possibilidade de conexão que apresentam, instituem conexão entre o regional e o mundial, e entre o local e o mundial, dependendo da extensão e densidade técnico-econômica das cadeias produtivas consideradas.

Este artigo apresenta a análise e discussão produzidas ao longo do desenvolvimento do projeto de pesquisa intitulado "Políticas de Desenvolvimento Regional e de Produção de Energia, Regulação e a Formação de Regiões Transfronteiriças na Ama-

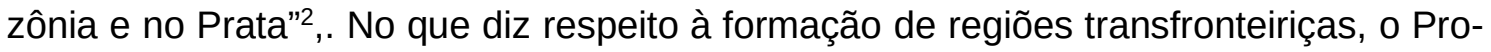
jeto partiu da hipótese de que cadeias produtivas territorializadas impõem articulação transfronteiriça concreta, ainda que subordinada aos gargalos de infraestrutura, às restrições de segurança e vigilância (NEVES et al., 2016), ou às diferenças de regulação entre países limítrofes. Dois pressupostos que alimentaram esta hipótese remetem aos investimentos binacionais em geração de energia elétrica (como a UHE de Itaipu, inaugurada em 1984), em rodovias, que antecederam à criação do Mercosul, e aos investimentos da Iniciativa para a Integração da Infraestrutura Regional Sulamericana-IIRSA ${ }^{3}$. O primeiro pressuposto diz respeito aos investimentos em infraestrutura como base para a criação de dinâmicas regionais com mais coesão e conexão em relação aos corredores de exportação. O segundo refere-se à inserção na economia globalizada por meio do desenvolvimento de cadeias produtivas.

De modo bastante simplificado, o método adotado neste trabalho foi a comparação, sincrônica e diatópica, de espaços submetidos a ações e processos de integração em escalas distintas da escala local. A comparação foi empregada para permitir a identificação de padrões e regularidades no uso e ocupação das terras, e no desenvolvimento de cadeias produtivas no momento presente. $O$ trabalho de campo desempenhou um papel importante no detalhamento empírico para a comparação entre as áreas selecionadas. Entre 2015 e 2017, foram realizados três trabalhos de campo para propiciar o levantamento de informações junto a órgãos de planejamento da esfera municipal e estadual, organizações da sociedade civil, organizações com ações de integração transfronteiriça, e agentes econômicos cuja atividade principal pressupõe em algum nível relações transfronteiriças. Optou-se pela comparação de duas áreas de tríplice fronteira pela dinâmica espacial do conjunto de cadeias produtivas agrupadas em quatro categorias, consideradas relevantes para inserção globalizada e para a integração sul americana, a saber: extrativa, agroalimentar, serviços e inovação.

As opções efetuadas apresentam importantes limitações em aspectos como diferença entre disponibilidade e acesso às informações nos diferentes países. Embora

\footnotetext{
${ }^{2}$ Chamada Pública MCTI/CNPQ/Universal 14/2014.

${ }^{3}$ A IIRSA foi criada em 2000, definindo eixos de integração a partir de corredores bioceânicos e integração da infraestrutura como pressupostos de inserção sul americana no mercado global.
} 
desde o início do Projeto este aspecto tenha sido levado em conta, as informações, produto de levantamento direto e entrevistas semiestruturadas, permitiram elucidar algumas questões e alimentar a análise efetuada. Ainda assim, deve-se sublinhar que houve maior quantidade de informação referente ao Brasil. Este é, aliás, um problema inerente aos estudos com metodologia comparada aplicada a espaços internacionais, donde a importância de estabelecer claramente as categorias e os critérios que permitem a comparação. Reiteramos, contudo, que determinadas interações transfronteiriças exigem certo distanciamento do contexto nacional como referencial exclusivo para sua interpretação e análise.

Mesmo que acordos bi ou trilaterais, políticas de abertura/interdição de terras e investimentos em infraestrutura orientem a ocupação de zonas de fronteira, a formação de regiões transfronteiriças vai além das ações intergovernamentais; ela pressupõe certa estabilidade e duração nas práticas e estratégias de agentes econômicos e de atores locais ${ }^{4}$, pois dispositivos de cooperação e intercâmbio podem ser interrompidos ou suprimidos. Considerando a evolução da ocupação da zona de fronteira no Brasil, selecionou-se dois espaços que apresentam níveis distintos de integração. O primeiro é a Tríplice fronteira Brasil-Bolívia-Peru, na porção leste e sul do estado do Acre, incluindo as aglomerações Cobija-Epitaciolândia-Brasileia; Plácido de CastroEvo Morales; Capixaba-Vila Comercial Rapiran Mapajo; Assis Brasil-Iñapari-Bolpebra. Considerando a localização de estoques e a exploração de recursos naturais, e as conexões para circulação e escoamento da produção, incluiu-se neste espaço o município de Guajará-Mirim (Rondônia) e os municípios bolivianos de Guayaramerín e Riberalta (Bolívia). O segundo, no sul do Brasil, é a Tríplice fronteira Argentina-BrasilParaguai. Tomou-se o oeste do estado do Paraná, tendo como ponto central o aglomerado urbano formado pelas cidades de Foz do Iguaçu, Puerto Iguazu e Ciudad Del Este que polariza esta região, e, para fins do estudo, estendeu-se até Posadas, capital da Província de Missiones, Argentina, e Encarnación, Paraguai.

\section{Transfronteiriço: ultrapassar sem contestar}

Uma análise da formação de regiões transfronteiriças obriga-nos, antes de mais nada, posicionar este termo frente ao de "fronteirização" (GRIMSON, 2003). Enquanto este último tende a acentuar as demarcações estabelecidas e consolidadas dos limites internacionais como problema, o primeiro pretende enfatizar o adensamento de relações entre agentes locais fronteiriços, pois é nesta situação que se pensam as relações internacionais. Steiman e Machado (2002), por exemplo, tratam da classificação das fronteiras como embate acirrado em vários momentos históricos e em diferentes campos de conhecimento, a partir de linhas que delimitam e separam territórios nacionais (MACHADO, 1998).

Muitos dos estudos que tratam das peculiaridades das zonas de fronteiras ressaltam os efeitos de uma dupla vinculação aos processos políticos, sociais e econômi-

\footnotetext{
${ }^{4}$ Emprestamos a definição de ator a partir de Lombard, Mesclier e Velut (2006) que recuperam a ampla definição de Brunet e Dollfus que, por sua vez, consideram a capacidade de definir uma estratégia com dimensão espacial.
} 
cos próprios a cada um dos Estados, à expansão da fronteira pela realização de grandes investimentos em infraestrutura em escala supranacional (CASTRO, 2012), e aos processos e interações inerentes aos efeitos de proximidade geográfica que caracterizam as relações entre cidades situadas na faixa de fronteira (ALBUQUERQUE, 2008; CARDIN, 2009; MACHADO, 1998; STEIMAN; MACHADO, 2002; RENOLDI, 2013; MAIDANA, 2016), a partir do tratamento de atividades como o turismo (MAIDANA, 2016), atividades ilícitas (GRIMSON, 2003, idem), ou da contestação de estereótipos das atividades comerciais históricas (RABOSSI, 2010). Essas análises ressaltam as imposições da excentricidade das fronteiras em relação às áreas cores, reduzindo a importância relativa dos processos regionais. Ora, tal excentricidade foi sendo progressivamente alterada pela dialética conexão - acessibilidade e por novas topologias.

O primeiro aspecto a ser considerado na formação de regiões transfronteiriças reside nos dois principais significados do prefixo trans: "para além de" e "através de". O sentido de "para além de" refere-se, em grande medida, ao movimento, à circulação além dos limites reconhecidos por diferentes grupos e pelos respectivos Estados limítrofes. Na perspectiva da análise geográfica adotada neste trabalho, o "para além de" implica que determinados grupos que controlam parte ou elos de uma cadeia produtiva com dinâmica própria são capazes de criar espaços mais ou menos coesos em função de determinada atividade econômica, sem necessariamente contestar a ordem jurídica dos limites entre os Estados, a força militar ou os símbolos nacionais. O sentido "através de" refere-se, por sua vez, à possibilidade de ultrapassar, de aproveitar os interstícios, de explorar as porosidades, de utilizar os meios tangíveis propiciados pelas ações e políticas de integração regional propostas pelos países limítrofes. Em outros termos, as conexões propiciadas pela infraestrutura viária abrem perspectivas para expansão geográfica de cadeias produtivas, sobretudo aquelas que envolvem utilização de terras. Assim, a dinâmica transfronteiriça pode ser impulsionada por acordos históricos de cooperação, como no caso da construção da ponte da Amizade (inaugurada em 1965) e a abertura da rodovia que liga Assunção (Paraguai) à Curitiba, e daí ao porto de Paranaguá (Brasil); a concessão de tarifas preferenciais para utilização de terminais portuários; construção de hidroelétricas; ou ainda pela criação de fundos de investimento, como o Fundo de Desenvolvimento da Bacia do Prata (FONPLATA), por exemplo.

É sempre bom lembrar que o estudo da problemática transfronteiriça não é recente. Perkmann e Sum (2002) consideraram que a retomada do interesse pelo tema deveu-se principalmente ao fato de que a condição transfronteiriça, ou melhor, as interações nesses espaços se tornaram objetivo mais ou menos explícito das estratégias espaciais de vários grupos e forças sociais dentro e além dos limites de determinados países, com força para acentuar diferenças locais (LOMBARD et al, 2006). Na América do Sul, a diluição dos interesses exclusivos do Estado pelas interações entre unidades territoriais de dois ou mais Estados foi igualmente apontada por vários autores (MACHADO, 1998; 2000; STEIMAN; MACHADO, 2002; BERTRAND; THERY, 2006; GUIBERT, 2009; VASQUEZ, 2009; BÜLHER, 2009; SCHWEITER, 2009; RABOSSI, 2010, entre outros) e mais recentemente por Ferrari e Dias (2013), Benedetti (2013, 2014), Carneiro Filho (2013), Silva (2012; 2017) entre outros. No nível regional, uma das questões permanentes relacionadas à infraestrutura energética diz respeito às 
escalas das redes de infraestrutura, notadamente energia elétrica, que a integração sul-americana demanda: a ampliação de sistemas e redes, cuja configuração foi durante um longo período voltada para o quadro nacional, para desenvolver conexões internacionais.

Tanto quanto a fronteira, que pode representar limite imposto, as noções de transfronteiriço, e, por extensão, de região transfronteiriça, são correlatas e recorrentes em vários períodos históricos das relações internacionais. O que caracteriza 0 transfronteiriço é a possibilidade e a capacidade dos diferentes atores em estabelecer estratégias espaciais sem necessariamente contestar os limites relativos à soberania territorial dos Estados (GUIBERT; LIGRONE, 2006), e saber explorar vantagens inerentes a esses limites, principalmente no que diz respeito às diferenças cambiais, aspecto importante para a balança comercial dos respectivos países.

A transfronteirização é, segundo Guibert e Ligrone (2006) o processo de valorização da fronteira como estratégia de vida da população que habita em cada uma das cidades, mas cuja manifestação pode ocorrer entre áreas urbanas, bacias hidrográficas, unidades de conservação e regiões. Ou seja, trata-se de um processo que desafia os estudos em geopolítica e geoeconomia. A ênfase no processo de transfronteirização estaria na ação de agentes e atores que, por meio de práticas cotidianas e estratégias de crescimento setorial, criam dinâmica particular, isto é regional. Trata-se, portanto, de processo que pressiona pela redução dos obstáculos à circulação, e ao mesmo tempo explora as diferenças dos respectivos sistemas de controle tributário, jurídico, de segurança e vigilância, por exemplo.

De modo distinto dos espaços institucionalizados no âmbito exclusivo do quadro nacional, as regiões transfronteiriças são produto das ações e práticas dos diferentes agentes com capacidade para realizar seus objetivos. Há que se notar, no entanto, que sua formação é submetida às imposições que regulamentam esses espaços. Segundo o IBGE, no Brasil, a faixa de fronteira, com legislação específica, recobre 588 municípios, 11 Unidades da Federação, e representa 16,6\% do território brasileiro. Assim, os diversos grupos econômicos elaboram estratégias de crescimento vertical e horizontal, submetidas às especificidades de localização, que englobam a aquisição de terras, métodos de produção, escoamento e comercialização da produção, sem, obrigatoriamente, contestar os limites dos Estados. Qualificar determinada região como transfronteiriça refere-se, portanto, às características de determinado espaço, localizado entre dois ou mais países, no qual os processos econômicos e sociais são produto da interação entre essas unidades espaciais submetidas a formas específicas de regulação setorial, ambiental e territorial, que podem criar dinâmica própria, e inserção em escalas mais amplas.

\section{Duas Tríplices Fronteiras}

Para desenvolver o estudo comparado, duas áreas de tríplice fronteira foram selecionadas segundo três pressupostos de natureza político-econômica: a) ser objeto de investimentos em infraestrutura vinculados à integração sul americana; b) integrar uma 
cadeia produtiva cuja distribuição espacial dos segmentos é transfronteiriça; c) possuir articulação da produção com mercado internacional e/ou global, e d) dispor de aglomerados urbanos nos dois países numa faixa de até $60 \mathrm{~km}$ que permita deslocamentos cotidianos regulares e frequentes em intervalo de tempo de no máximo uma hora e trinta minutos. Assim, foi possível caracterizar dois níveis de conexão: na escala da aglomeração urbana e na escala das cadeias produtivas.

A delimitação das áreas para comparação implicou em adequar diferentes maIhas político administrativas que abrangem províncias, departamentos, estados, municípios e cidades. É preciso, no entanto, ter cuidado com as aproximações. A definição de urbano e rural que incide sobre a contagem da população é diferente segundo os países considerados: enquanto Brasil e Paraguai definem população urbana por critérios administrativos, sede municipal e cabecera de departamentos e distritos, Argentina e Bolívia estabelecem número mínimo de população, 2.000 habitantes, e Peru enfatiza o número mínimo de 100 construções ocupadas por contiguidade e critérios administrativos, em casos de exceção ${ }^{5}$. Para efeitos deste trabalho, denominou-se Tríplice Fronteira Norte e Tríplice Fronteira Sul as áreas nas quais a hipótese de formação de regiões transfronteiriças foi testada (Mapa 1).

Mapa 1. Identificação das áreas de estudo: Tríplice Fronteira Norte e Tríplice Fronteira Sul

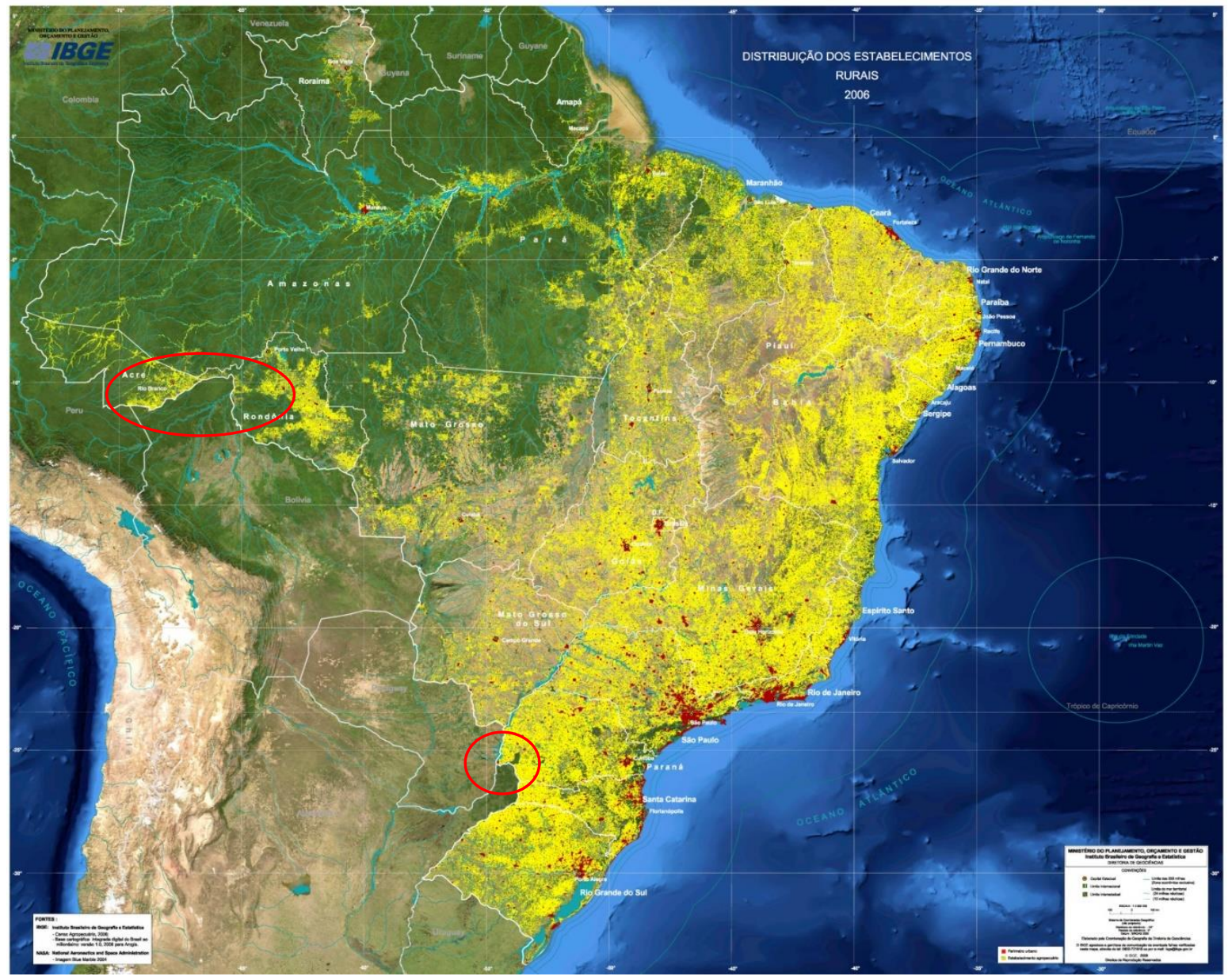

Fonte: Adaptado de IBGE (2009).

Nota: As áreas de estudo estão identificadas pelas circunferências em vermelho.

${ }^{5}$ Conforme dados da CEPAL (2013) e Lima (2007). 
Quadro 1. Área de Estudo Ampliada: População e Densidade Demográfica

\begin{tabular}{|c|c|c|c|c|c|}
\hline Fronteira & $\begin{array}{l}\text { Países } \\
\text { limítrofes }\end{array}$ & $\begin{array}{l}\text { Trecho Percorrido } \\
\text { em trabalho de campo }\end{array}$ & Cidades & População & $\begin{array}{c}\text { Densidade } \\
\text { demográfica } \\
(\text { hab./km²) }\end{array}$ \\
\hline \multirow{13}{*}{ Norte } & \multirow{10}{*}{$\begin{array}{l}\text { Brasil- } \\
\text { Bolivia }\end{array}$} & \multirow{3}{*}{ Cobija-Epitaciolandia-Brasileia } & Cobija & 58.783 & 90,44 \\
\hline & & & Epitaciolandia & 17.038 & 9,13 \\
\hline & & & Brasiléia & 24.311 & 6,21 \\
\hline & & \multirow{2}{*}{$\begin{array}{l}\text { Placido de Castro - Evo Mora- } \\
\text { les }\end{array}$} & Plácido de Castro & 18.336 & 8,86 \\
\hline & & & Evo Morales & $s / d$ & $s / d$ \\
\hline & & \multirow{2}{*}{$\begin{array}{l}\text { Capixaba - Vila Comercial } \\
\text { Rapiran Mapajo }\end{array}$} & Capixaba & 10.820 & $s / d$ \\
\hline & & & $\begin{array}{l}\text { Vila Comercial } \\
\text { Rapiran Mapajo }\end{array}$ & $s / d$ & $s / d$ \\
\hline & & \multirow{3}{*}{$\begin{array}{l}\text { Guajara Mirim-Guayaramerín- } \\
\text { Riberalta }\end{array}$} & Guajamirín & 46.230 & 1,89 \\
\hline & & & Guayamerin & 46.706 & 3,2 \\
\hline & & & Riberalta & 99.070 & 4,9 \\
\hline & \multirow{3}{*}{$\begin{array}{l}\text { Brasil- } \\
\text { Bolivia- } \\
\text { Peru }\end{array}$} & \multirow{3}{*}{ Assis Brasil - Iñapari-Bolpebra } & Assis Brasil & 6863 & 1,22 \\
\hline & & & Iñapari & 1500 & 0,05 \\
\hline & & & Bolpebra & 400 & 0,1 \\
\hline \multirow{7}{*}{ Sul } & \multirow{3}{*}{$\begin{array}{l}\text { Argentina- } \\
\text { Brasil- } \\
\text { Paraguai }\end{array}$} & \multirow{3}{*}{$\begin{array}{l}\text { Foz do Iguaçu - } \\
\text { Ciudad Del Este - } \\
\text { Puerto Iguazu }\end{array}$} & Foz do Iguaçu & 263.782 & 432,28 \\
\hline & & & Ciudad Del Este & 387.755 & 2825,2 \\
\hline & & & Puerto Iguazu & 82.849 & 109,15 \\
\hline & \multirow{2}{*}{$\begin{array}{l}\text { Argentina- } \\
\text { Paraguai }\end{array}$} & \multirow{2}{*}{ Posadas-Encarnación } & Encarnación & 127.527 & 46,54 \\
\hline & & & Posadas & 386.387 & 37 \\
\hline & \multirow{2}{*}{$\begin{array}{l}\text { Argentina- } \\
\text { Brasil }\end{array}$} & \multirow{2}{*}{ Andresito-Capanema } & Capanema & 19.320 & 4,61 \\
\hline & & & Comandante Andresito & 28.000 & 13,8 \\
\hline
\end{tabular}

Fontes: IBGE; IBGE, 2016; INE; IGN; DIRECCIÓN..., 2015.

A distribuição espacial da população e o tamanho das cidades mereceram atenção especial, pois núcleos urbanos mais ou menos articulados, complementares e interdependentes asseguram a frequência dos fluxos cotidianos. Alguns autores como Reolon (2013) defendem a ideia de que Foz do Iguaçu é, na verdade, o núcleo principal de uma única aglomeração urbana intermunicipal e transnacional composta pelas cidades Santa Terezinha de Itaipu e São Miguel do Iguaçu, no oeste paranaense; as paraguaias Ciudad del Este, Hernandarias, Presidente Franco e Minga Guazú; e a argentina Puerto Iguazú. Defronta-se com um problema particular na medida em que, na escala supranacional, o sistema urbano em formação está sujeito às políticas nacionais de integração continental, e à abertura de fronteiras econômicas (EGLER, 2011, 2015; MOURA; PÊGO, 2016; CEPAL, 2012). No entanto, a intensificação do crescimento de aglomerados urbanos, formando manchas urbanas transfronteiriças impõem formas de interação, e abrem perspectivas para o desenvolvimento de atividades econômicas. Em ambas as áreas selecionadas para estudo, a presença de Universidades é fato importante para as interações transfronteiriças e ponto relevante da pauta de regulação dos serviços médicos, principalmente na Tríplice Fronteira Sul.

Nas áreas transfronteiriças, na confirmação da hipótese de formação de regiões desta natureza, estas seriam definidas pela proximidade de cidades, aglomerados e vilarejos com intera- 
ção e dinâmica que transcendem os limites de cada um dos Estados; a centralidade assegurada por cidades de porte médio, mas cujo somatório das respectivas populações é da ordem de 1 milhão de habitantes, e cujas funções que lhes associam permitem integrar cadeias produtivas e de serviços que operam no nível internacional e/ou exploram os diferentes sistemas de regulação. Os aglomerados urbanos retratam igualmente a dependência histórica dos intercâmbios transfronteiriços, sobretudo no litoral paraguaio ${ }^{6}$ (VASQUEZ, 2009; SCHWEITER, 2009). Há, no entanto, uma tensão entre as demandas de conexão extra locais e de fluidez para escoamento da produção para o mercado global, por um lado, e, por outro, o terreno regional como força de vantagens competitivas.

A comparação entre volume da população e densidade demográfica é útil porque dela ressaltam dois aspectos: o nível da menor unidade de representação político-administrativa e a referência espacial para capturar informações sobre dinâmica econômica, social e ambiental como os municípios, no caso de Brasil e Bolívia, os distritos, no Peru e Argentina e Paraguai. Os aglomerados urbanos de todos os tamanhos, cidades e vilarejos, representam potencial e/ou intensificação de intercâmbios e diversificação nas configurações urbanas e rururbanas em espaços transfronteiriços; a natureza das relações entre esses aglomerados e as áreas rurais, por um lado, e entre áreas rurais, por outro, pode representar um potencial para o desenvolvimento de sistemas regionais transfronteiriços.

\section{A perspectiva comparada}

De modo bastante simplificado, o método adotado para o desenvolvimento do Projeto pressupôs a comparação, no tempo e no espaço, entre as situações de uma mesma região ou entre regiões diferentes, submetidas a processos semelhantes, mesmo que defasados no tempo. Neste projeto, a comparação foi empregada para permitir a identificação de padrões e regularidades no uso e ocupação das terras e no desenvolvimento de cadeias produtivas em duas áreas distintas. $\mathrm{O}$ tipo de investigação efetuada associou empiria e comparação, uma vez que o método se baseia no estudo das características que conferem individualidade a determinados espaços ou conjunto de lugares articulados entre si. No plano epistemológico, a comparação orientou a análise a fim de se evitar os riscos de descrições exclusivas e exaustivas de caráter idiográfico. No plano analítico, a comparação foi útil para o reagrupamento dos principais dados e processos e a caracterização de estruturas regionais para identificar particularidades e diferenças contextuais.

Foram três perguntas iniciais que balizaram a análise: o que, por que e como comparar? O Quadro 1 define os critérios empregados na caracterização das áreas selecionadas, conforme assinaladas no Mapa 1. Considerando as características mencionadas, as duas áreas representam de modo adequado a situação de tríplice fronteira nas quais os modelos de mobilização de recursos naturais, dotação de infraestrutura, e os níveis de conexão modificam as condições de acesso e inserção na economia global, gerando dinâmica regional própria. A noção de cadeia produtiva exerce o papel de categoria central para a análise.

\footnotetext{
${ }^{6}$ Litoral paraguaio, denominação geográfica específica para as áreas baixas banhadas pelo rio Paraná.
} 
Quadro 2. Critérios de comparação

\begin{tabular}{|c|c|c|c|}
\hline Critérios & Elementos & Tríplice Fronteira Sul & Tríplice Fronteira Norte \\
\hline \multirow{2}{*}{ Localização } & Faixa de Latitude & $23^{\circ} \mathrm{S}$ e $30^{\circ} \mathrm{S}$ & $07^{\circ} \mathrm{S}$ e $13^{\circ} \mathrm{S}$ \\
\hline & Condições climáticas & Subtropicalidade & Tropicalidade \\
\hline \multirow[t]{2}{*}{ Posição } & $\begin{array}{l}\text { Distância/proximidade em } \\
\text { relação aos centros econô- } \\
\text { micos nacionais }\end{array}$ & Excêntrica & Excêntrica \\
\hline & $\begin{array}{l}\text { Conexão às redes de infra- } \\
\text { estrutura }\end{array}$ & Elevada & Media/Fraca \\
\hline \multirow{3}{*}{$\begin{array}{l}\text { Interações Espaciais/ } \\
\text { Situação }\end{array}$} & Urbana-urbana & Intensas, cotidianas & Rarefeitas, cotidianas \\
\hline & Urbana-rural & Regulares, frequentes & Regulares, ocasionais \\
\hline & Rural-Rural & Regulares, frequentes & Sazonais \\
\hline Densidade & $\begin{array}{l}\text { Demográfica, Econômica, } \\
\text { Institucional }\end{array}$ & $\begin{array}{l}\text { Elevadas, } \\
\text { consolidada }\end{array}$ & $\begin{array}{l}\text { Média a baixa, Frente Extrati- } \\
\text { va }\end{array}$ \\
\hline
\end{tabular}

Fonte: Elaboração própria

Tropicalidade e subtropicalidade são condições que interferem nas formas de relevo - terrenos de planalto - em parte com cobertura florestal original, fisionomia e composição, bastante diferenciadas, bem como a fertilidade natural associada aos derrames basálticos no oeste do Paraná, e restrições impostas pelo clima tropical/equatorial à fertilidade natural na fronteira trinacional norte. Nesta última, a cobertura florestal é condição obrigatória para a manutenção da fertilidade dos solos e o desenvolvimento de cadeias produtivas de extração de produtos florestais não lenhosos e dependentes da biodiversidade.

Na América do Sul, não se pode negligenciar a presença de espaços marginais com baixa densidade demográfica no final do século $X X$, onde a expansão da frente de criação de gado, nos anos de 1990, reconfigurou a ocupação na fronteira entre Brasil e Paraguai. No Chaco paraguaio emergiu, nas palavras de Vasquez (2009, p. 404) "pela primeira vez um espaço econômico transfronteiriço". A abertura de frente agrícola que ultrapassou os limites internacionais (BÜHLER, 2009) originou, ao longo do tempo, espaços bem conectados ao mercado mundial na Bacia do Prata, formando um eixo de grande circulação, de maior densidade econômica, e com a implantação de cidades como base de apoio à produção agrícola. Simultaneamente, a presença de frentes extrativas situadas ao norte, na Amazônia Ocidental, mais especificamente no Acre, sinaliza a reprodução de modelos já esgotados de expansão produtiva.

Esses espaços "marginais", de ocupação recente, têm em comum a presença de população tradicional, indígena e pequenos agricultores. O adensamento urbano na Tríplice Fronteira Sul, a construção de hidroelétricas e o consequente deslocamento de população resultaram na contração e expulsão de etnias guaranis, bem como provocaram o adensamento populacional em algumas cidades. A Tríplice Fronteira Norte, conheceu ciclos extrativos em diferentes momentos. À antiga ocupação para a exploração da borracha, na segunda metade do século XIX, no Brasil, Bolívia e Peru sucedeu uma segunda frente de exploração para extração do látex direcionada principalmente para o Acre, na década de 1940. Esta segunda frente tem origem no deslocamento 
de população atingida pela seca, em particular nos estados do Ceará, Piauí e Rio Grande do Norte. Esgotadas as possibilidades de prolongamento deste segundo ciclo de exploração de seringueiras (Hevea brasiliensis), os soldados da borracha, nome pelo qual ficaram conhecidos esses nordestinos refugiados da seca, passaram a se dedicar à agricultura de subsistência e à coleta da castanha da Amazônia (Bertholletia excelsa). Assim, nessa área, a presença da floresta possibilita a permanência de diferentes grupos e etnias indígenas e de seringueiros, mas que estão progressivamente sendo confinados em categorias específicas de unidades de conservação como reservas extrativistas, ou em Terras Indígenas. A expansão de outras cadeias exerce pressão para a redução dessas unidades e acentua os processos erosivos.

\section{Cadeias Produtivas e Organização Espacial}

Acatou-se a seguinte definição para cadeia produtiva: conjunto de etapas consecutivas pelas quais insumos são transformados e cuja divisão territorial do trabalho implica em articulação no nível regional. Esta definição partiu daquela elaborada por Lastres e Cassiolato (2003), mas, à diferença destes autores, considera a escala regional como nível adequado para articulação de parte da cadeia. Sobre este último ponto, procedeu-se à aproximação entre cadeia produtiva e a noção de cadeia de valor, uma vez que esta última é, por definição, geograficamente concentrada e envolve estoques de recursos e infraestrutura (KUPFER, 2015), o que permitiria reforçar níveis de interação, aproveitar a disponibilidade de infraestrutura, desenvolver especificidades de tipo complementar e de organização, sendo portanto, tributária do ambiente e da densidade institucionais. As cadeias podem apoiar-se em três lógicas: técnica, de organização e de inovação. A primeira reforçando o encadeamento sucessivo de etapas para transformação de determinado produto, a segunda pela articulação de empresas por meio de fluxos de mercadorias e capital, e a terceira pela proximidade geográfica do conjunto de atividades e de agentes que compartilham conhecimento. No plano organizacional, as cadeias podem prescindir das fronteiras internacionais ou, ao contrário, aproveitar temporariamente as diferenças de regulação entre países, principalmente no que diz respeito às diferenças cambiais e às condições de acesso aos recursos naturais.

É importante lembrar que a noção de cadeia produtiva remete também a um tipo de literatura vinculado à economia industrial que se preocupa com o contexto concorrencial e as estratégias de crescimento de empresas (DÉTRIE et al., 1997). Em parte, a coordenação entre cada uma das etapas de uma cadeia pode levar à formação de grupos e associações de empresas e de cooperativas. Ou seja, duas modalidades de organização predominam: integração vertical de empresas e cooperativismo. No caso das duas áreas de estudo, as cooperativas desempenham papel importante no desenvolvimento de determinadas cadeias. Há, de modo evidente, diferenças significativas em termos de escala, densidade de atividades, de integração vertical e horizontal, e articulação com os operadores de logística, mas a organização da produção com base no cooperativismo é um dado comum.

Conforme já assinalado, adotou-se como definição de cadeia produtiva a forma geograficamente organizada da produção que pressupõe etapas sucessivas na transformação e beneficiamento de um produto e as interações entre agentes em torno de um mesmo produto. Definiu-se 
um determinado número de cadeias consideradas como as mais relevantes a partir de dados secundários, de observações realizadas em campo, e de entrevistas com atores locais São elas: castanha da Amazônia, madeira, látex, ouro, proteína animal, grãos, turismo, serviços médicos, energia elétrica, fármacos/cosméticos e biotecnologia (Quadro 3). Essas cadeias foram agrupadas em quatro categorias: extrativa, agroalimentar, serviços e inovação.

Quadro 3. Presença de Cadeias Produtivas nas Áreas Selecionadas para Estudo

\begin{tabular}{|l|l|l|c|}
\hline \multirow{4}{*}{ Categoria } & \multicolumn{2}{|c|}{ Cadeia } & \multicolumn{2}{c|}{ Presença e Dinamismo } \\
\cline { 3 - 4 } & & $\begin{array}{c}\text { Brasil-Bolívia- } \\
\text { Peru }\end{array}$ & $\begin{array}{c}\text { Argentina- } \\
\text { Brasil-Paraguai }\end{array}$ \\
\hline \multirow{5}{*}{ Extrativa } & Castanha & & inexistente \\
\cline { 2 - 4 } & Madeira & & inexistente \\
\cline { 2 - 4 } & Látex & & inexistente \\
\cline { 2 - 4 } & Ouro & & \\
\hline \multirow{3}{*}{ Agroalimentar } & Proteína animal & & \\
\cline { 2 - 4 } & Grãos & & \\
\hline \multirow{3}{*}{ Serviços } & Turismo & & \\
\cline { 2 - 4 } & Médicos & & \\
\cline { 2 - 4 } & Energia elétrica & & \\
\hline \multirow{2}{*}{ Inovação } & Fármacos/Cosméticos & & \\
\cline { 2 - 4 } & Biotecnologia & & \\
\hline
\end{tabular}

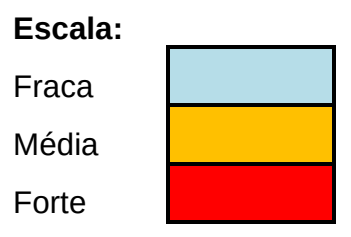

Fonte: Elaboração própria.

As cadeias vinculadas à inovação estão, em geral, agrupadas em três tipos: biotecnologia, novos materiais e tecnologia de informação e comunicação. Na categoria inovação, foram definidas duas cadeias que podem ser consideradas desdobramentos da cadeia extrativa. $\mathrm{O}$ que as individualiza? O emprego de produtos florestais não lenhosos que correspondem basicamente às resinas, cipós, óleos, sementes, plantas ornamentais e medicinais. Deste conjunto, alguns produtos podem ser destinados ao consumo in natura, ou após beneficiamento primário. Neste último caso, inclui-se a castanha da Amazônia, produto que integra a categoria cadeia extrativa. Ou seja, alguns produtos, como a castanha, podem integrar diferentes cadeias como a extrativa, a agroalimentar e de inovação. O que distinguiria, então, as cadeias, uma vez que os produtos oriundos da extração têm sido valorizados como componentes da biodiversidade? Na distinção entre cadeias 
extrativas e de inovação, adotou-se como princípio o nível de investimento em pesquisa e desenvolvimento tecnológico. Ou seja, o conteúdo em P\&D por unidade produzida é elevado e requer grandes níveis de organização e escala de investimentos.

Biodiversidade é definida, segundo a Convenção da Diversidade Biológica (CDB), como a variabilidade de organismos vivos de todas as origens, compreendendo, dentre outros, os ecossistemas terrestres, marinhos e outros ecossistemas aquáticos e complexos ecológicos dos quais os diferentes ecossistemas fazem parte; compreende ainda diversidade no seio das espécies e entre espécies, assim como nos ecossistemas. Envolve, portanto, a diversidade em três níveis: ecossistemas, espécies e genes. Às aplicações de tecnologia que utilizem sistemas biológicos vivos, ou seus derivados, para produzir ou modificar produtos para utilização específica denomina-se biotecnologia. Esta abordagem fundamenta a categoria biodiversidade que, para fins de análise, foi subdividida em duas cadeias: fármacos/cosméticos e biotecnologia. Ou seja, de modo muito resumido, na produção de fármacos/cosméticos, a tecnologia empregada orienta para o aproveitamento de uma molécula específica, o princípio ativo de determinada planta, por exemplo, que será sintetizado; enquanto a biotecnologia refere-se ao aproveitamento do conjunto de informações genéticas para formar novos medicamentos, organismos (transgênicos), enzimas para produção de etanol celulósico, etc. Uma hipótese levantada e que necessita comprovação diz respeito à possibilidade de que a produção de celulose constitua um elo da cadeia de fármacos, sobretudo na fronteira trinacional sul.

\section{Regiões Transfronteiriças}

Nas regiões transfronteiriças, as cadeias produtivas indicam algumas regularidades e padrões de interdependência entre localização material da produção, disponibilidade de terras e de infraestrutura. As cadeias de commodities agrícolas e de proteína animal têm necessidade imperiosa de terras e água. A organização da cadeia requer, além disso, relações técnicas e econômicas entre as diferentes atividades produtivas tanto no aspecto funcional, como no território. Nesse sentido, a qualidade da infraestrutura de energia elétrica, transporte, comunicação e financeira conferem relativa autonomia e densidade para determinadas regiões. Melhoramento genético, automação de linha de produção e câmaras frigoríficas são fortemente dependentes da oferta de energia elétrica com estabilidade, frequência adequada, e regularidade, e da cobertura da rede de distribuição. A intensidade das interações urbanas se manifesta de modo concreto e cotidiano na migração pendular de trabalhadores diaristas, no comércio de produtos básicos, e em serviços médicos. Este é o caso dos fluxos entre Foz do Iguaçu e Ciudad Del Leste e Puerto Iguaçu, e em menor escala entre Cobija e Brasilléia e Epitaciolândia

\section{Na Fronteira Trinacional Norte a predominância de cadeias extrativas}

As cadeias produtivas que estão na base de uma economia extrativa (castanha da Amazônia, madeira, látex e ouro) têm presença e efeitos diferenciados em cada uma das regiões consideradas. Enquanto a exploração mineral, principalmente ouro, constitui cadeia de ciclo extrativo com 
pouco ou nenhum beneficiamento in loco, o beneficiamento da madeira em tora e da castanha, ao contrário, vêm criando uma dinâmica regional na Fronteira Trinacional Norte, Brasil-Bolívia-Peru. Trata-se de região que dispõe de cobertura florestal significativa (Mapa 2) que conta com reservas extrativistas, várias unidades de conservação e terras indígenas. Os estoques e fluxos de castanha, por exemplo, estão diretamente associados à presença de matas e florestas, enquanto os fluxos de madeira em tora se distinguem entre extração legal e ilegal nas áreas de floresta natural, e extração a partir de reflorestamento com fins industriais, ou oriunda de áreas de manejo florestal. É sempre bom lembrar que muitos dos produtos passíveis de aproveitamento na indústria de fármacos e de cosméticos pressupõem, na base da produção, conhecimento tradicional associado, o que permite melhor aproveitamento dos princípios ativos, donde a imprescindível presença dessa população. 
Mapa 2. Tríplice Fronteira Argentina-Brasil-Paraguai: mapa síntese

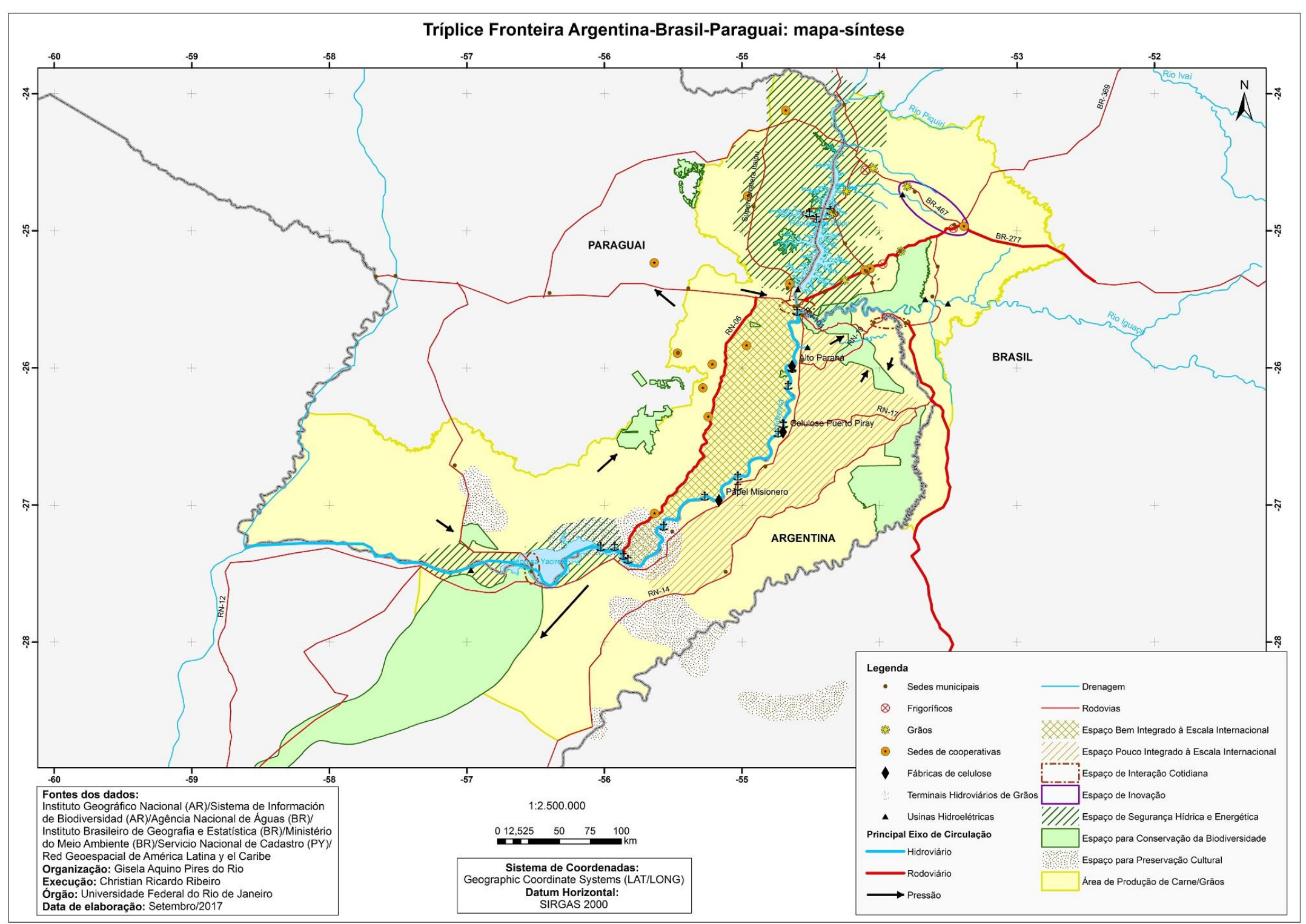

R. Bras. Geogr., Rio de Janeiro, v. 65, n. 1, p. 43-70, jan./jun. 2020 
$\mathrm{Na}$ exploração e comercialização da castanha da Amazônia, há expressivo contingente de indivíduos envolvidos na coleta, beneficiamento, atacado e varejo, uma estrutura de organização que engloba empresas de grande porte, cooperativas, rede de coletores, e negociantes internacionais (traders). Presente de um lado e de outro da fronteira entre Brasil e Bolívia (Gráfico 1), tem estrutura de beneficiamento tanto em Brasiléia, como em Cobija e Riberalta, e menor produção no lado peruano. No entanto, o crescimento da participação do Peru, sobretudo aquela produção oriunda da região de Madre de Dios, consiste em rota mais recente e em competição com a rota boliviana para exportação desse produto, via portos do Pacífico.

Gráfico 1. Produção de Castanha da Amazônia (toneladas $x$ ano)

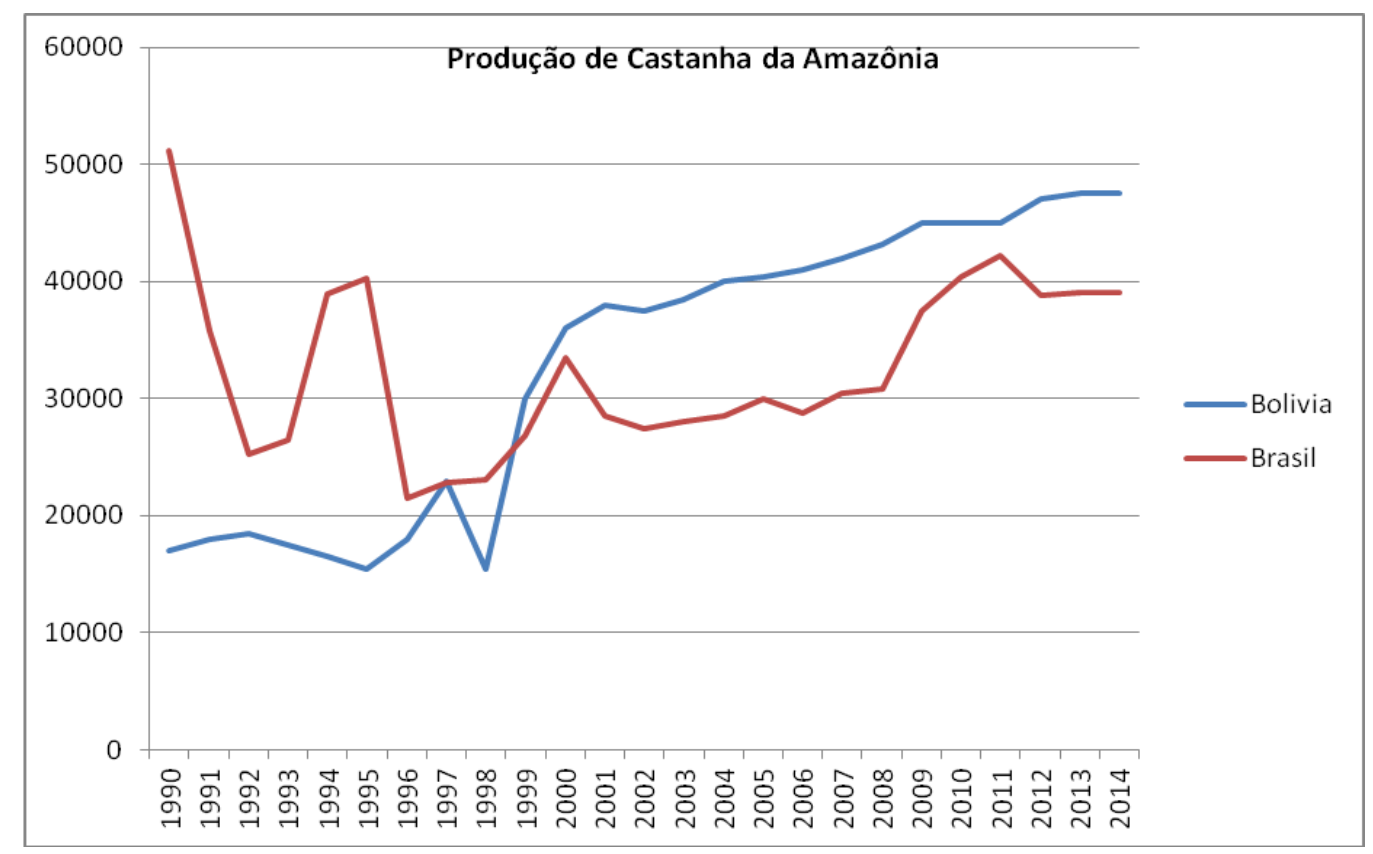

Fonte: FAOSTAT, 2015

No beneficiamento da castanha, reside a oportunidade de gerar emprego e renda. Esta etapa, requer mais disponibilidade de capital e infraestrutura. A organização do beneficiamento da castanha por meio de cooperativas é relativamente recente (BAYMA et al., 2014), mas constitui um modo de organização eficiente para obter ganhos de escala a fim de atender à crescente demanda representada pelo consumo in natura, pela indústria de alimentos e de cosméticos. Do lado boliviano, as áreas com maior densidade de floresta são a base para o sistema de exploração organizado por três grandes empresas em cerca de $100.000 \mathrm{~km}^{2}$, envolvendo um contingente de aproximadamente 15.000 indivíduos, segundo informações da Autoridad de Fiscalización y Control Social de Empresas. Três empresas- Manutata S.A, Amazonas, S.A, e Beneficiadora de Almendra Harold Claure Lens- beneficiam cerca de 5.000 toneladas/ano. Manutata S.A, por exemplo, apresentou em 2011 uma relação produção/exportação da ordem de 130\%, indicando que sua capacidade de exportação é bem superior à produção própria. A empresa boliviana EBA 
(Empresa Boliviana de Almendras) ${ }^{7}$, com sede em Sena, departamento de Pando, detém cerca de $2 \%$ do mercado de exportação, e conta com representação comercial - EBA Europa - em Hamburgo, Alemanha, desde 2013. Os fluxos deste produto ligam áreas de extração e locais de armazenamento às unidades de beneficiamento e exportação localizadas na Bolívia, e projetam Cobija e Riberalta como principais clusters de castanha beneficiada para o mercado mundial.

A extensão da cadeia tem do lado brasileiro a presença de cooperativas. A COOPERACRE, por exemplo, com sede em Rio Branco, fundada em 2001, conta com 2.256 cooperados; 30 galpões comunitários, 4 galpões centrais para armazenamento e três unidades de processamento em Rio Branco, Xapuri e Brasileia (Cooperativa Agropecuária Extrativista de Xapuri (CAEX), Cooperativa Agroextrativista dos Produtores de Epitaciolândia e Brasileia (CAPEB), e de unidades de secagem em mais 11 municípios no estado do Acre. A circulação do produto entre os países é, portanto, associada à atuação das cooperativas que dispõem de meios para escoar a produção, concentrada em determinados períodos do ano. A organização da produção extrativa florestal de produtos não madeireiros e de madeira conta ainda com apoio da WWF- Brasil, Central de Trabalhadores da Amazônia (CTA), SOS Amazônia, Instituto de Manejo e Certificação Florestal e Agrícola (IMAFLORA), de políticas estaduais como o Programa de Desenvolvimento Sustentável do Estado do Acre (PDSA) com financiamento do Banco Interamericano de desenvolvimento.

A ocupação de áreas abertas para a expansão de cadeias de proteína animal e de grãos é relativamente recente, mas a pressão sobre áreas ocupadas com população indígena, seringueira, e com pequenos produtores familiares é marcante. A redução da floresta pela expansão dessas cadeias, que exigem obrigatoriamente a derrubada de matas, pode comprometer a produção e exportação de castanha, assim como a pressão da exploração da madeira consiste em ameaça efetiva para sua manutenção. No caso da madeira, três cidades, Rio Branco e Capixaba, no lado brasileiro, e Cobija, no lado boliviano, polarizam os fluxos de madeira. Num raio de aproximadamente $150 \mathrm{~km}$ em torno dessas cidades estão localizadas as áreas de extração de madeira em tora. A circulação deste produto é sazonal e sujeita a diferenças significativas na regulação e nos critérios de manejo deste produto. A presença polos moveleiros em Xapuri, Epitaciolândia, Brasiléia e Cobija, completa, em pequena escala, a cadeia da madeira na região. O principal destino da produção em pranchas é o mercado extra regional.

Além disto, essas áreas ainda dispõem de superfícies com cobertura florestal que podem desempenhar um papel considerável na formação e aproveitamento do patrimônio genético a partir da mobilização de conhecimento tradicional, condição necessária para o aproveitamento da biodiversidade. A questão reside nas possibilidades abertas pela presença da floresta densa, no potencial de inovação, e dinamismo em escala regional que possam criar estratégias regionais inovadoras.

A ponte da Integração que permite a ligação entre a cidade de Iñapari, Peru, e Assis Brasil, Brasil, inaugurada em 2006, ainda apresenta capacidade ociosa em termos de fluxos tanto de mercadorias, como turísticos e cotidianos. Se os relatos dos entrevistados indicam a formação de famílias que habitam de um lado e de outro da fronteira, o tamanho urbano das cidades, no entan-

\footnotetext{
7 Em 2018, operou-se a fusão de três empresas- Lacteos de Bolivia (Lactesbol), Empresa Pública Productiva Apicola (Promiel) e Empresa Boliviana de Almendras (EBA) -, formando a Empresa Boliviana de Alimentos y Derivados (EBA). Neste trabalho, a sigla EBA refere-se à Empresa Boliviana de Almendras, criada em 2009.
} 
to, não é suficiente para gerar fluxos pendulares e de mercadorias intensos e regulares, ao contrário do que ocorre, por exemplo, entre as cidades de Cobija e Epitaciolândia-Brasiléia.

\section{Na Fronteira Trinacional Sul uma região transfronteiriça em consolidação}

Em contraste às baixas densidades demográfica e econômica observadas na tríplice fronteira norte, no sul, os processos de organização e reestruturação espacial estão mais claramente definidos, e contam relativamente com maior número de trabalhos publicados (RIBEIRO, 2001; MACHADO, 2005; HAESBAERT, 2009; MACAGNO, L., MONTENEGRO, S.; BÉLIVEAU, V. (Orgs.), 2011; MACHADO et al., 2014; CARNEIRO FILHO, 2013; GUIBERT et al., 2009, entre outros). Nesta área, a expansão de cadeias de proteína animal e de grãos tem papel importante na configuração da região transfronteiriça, bem como os investimentos na construção de usinas hidrelétricas do porte de Itaipu e Yacyretá.

Estas últimas induziram o deslocamento de significativo contingente de população agrícola que teve duas consequências diretas: por um lado, a abertura de terras para cultivo de commodities agrícolas em direção ao litoral do Paraguai (ao longo do rio Paraná), e ao norte do Brasil, e, por outro, a concentração da população urbana decorrente de deslocamentos forçados e/ou incentivados, sobretudo no lado paraguaio, que teve maior perda de terras para preenchimento do lago de Yacyretá. Localizada a $400 \mathrm{~km}$ à jusante de Itaipu, esta usina hidroelétrica levou 37 anos para sua construção ${ }^{8}$, e o alteamamento da barragem para sua cota máxima de operação (83 m), atingida em 2011, acrescentou à área de inundação originalmente prevista de 110.000 ha mais 55.000 ha. Ou seja, dos 124.000 ha inundados, $80 \%$ foi em território paraguaio (CAUSARANO, 2011).

Enquanto o lago de Itaipu, situado à montante da ponte da Amizade, é hoje rota para a exportação de soja em direção aos portos de Paranaguá e Santos, a UHE Yacyretá, à jusante, não constitui efetivamente um barramento ao tráfego de barcaças no rio Paraná: a construção de canal de navegação e eclusa permite que as exportações paraguaias por via fluvial representem cerca de $85 \%$ do comércio exterior do país. A instalação de 11 terminais hidroviários ao longo do rio Paraná pelas empresas que comercializam e exportam grãos integram os serviços de logística, dando os contornos, junto com a Ruta Nacional 6, dos espaços conectados ao mercado global.

\footnotetext{
8 O acordo para a construção da UHE de Yacyretá data de 1973, mas a primeira turbina entrou em operação em 1994,e a inauguração da usina com todas as turbinas ocorreu em 2011.
} 
Mapa 3. Tríplice Fronteira Brasil-Bolívia-Peru: mapa síntese

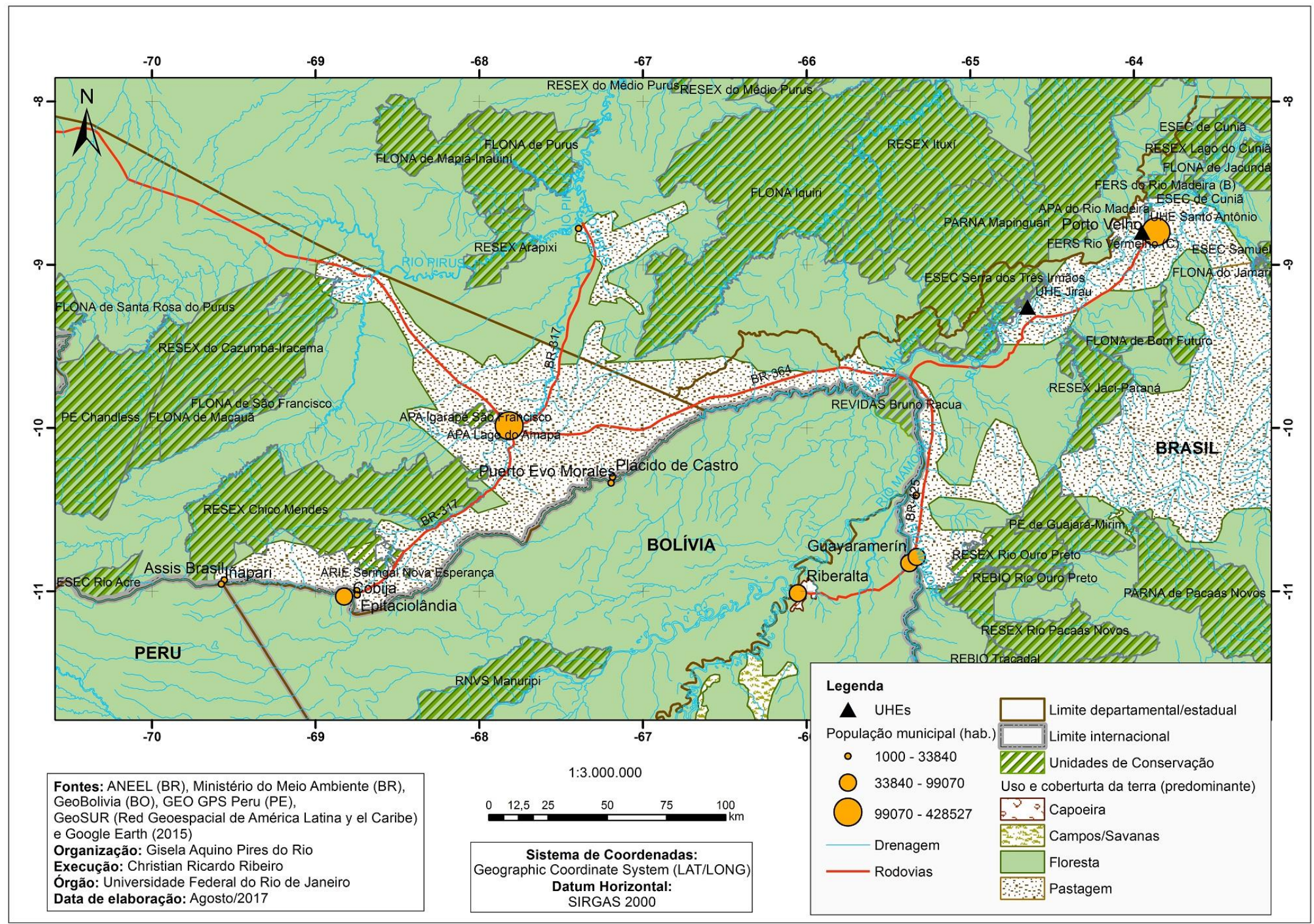


Esta região trinacional em consolidação configura-se a partir de dois eixos principais de circulação, rodoviário e hidroviário, que conectam principais aglomerados urbanos. Há acentuado papel da hidrovia Paraná e dos portos fluviais na circulação regional no escoamento da produção agrícola, principalmente do Paraguai. Ao longo do rio Paraná, as referências às cidades ou localidades indicam este aspecto. Na Província de Missiones, Departamento de Iguazu, cuja produção de mate e madeira é significativa, cidades como Puerto Esperanza, Puerto Iguazu ou Puerto Liberdad ilustram este aspecto. Trata-se de um espaço heterogêneo configurado a partir de quatro cadeias produtivas: proteína animal, grãos, turismo e produtos madeireiros (pranchas e papel e celulose).

O crescimento da produção de grãos contou com um nível de organização apoiado em cooperativas de grande porte, como a LAR, e com a presença dos principais grupos transnacionais da indústria agroalimentar como Cargill, ADM, Dreyfus, e empresas de capital chinês e sul coreano, principalmente nos departamentos de Alto Paraná e Itapúa, no Paraguai.

A configuração da produção das cadeias de proteína animal e de grãos tiveram por base a ocupação inicial da abertura de terra do lado brasileiro, nas décadas de 1950 e 1960, com pequenas e médias propriedades nas quais se desenvolveu a pecuária de pequeno porte, porcinocultura e avicultura, associada à produção de grãos, e da expansão da frente agrícola no Paraguai a partir dos anos de 1970. As principais cooperativas foram criadas nos anos de 1960 e início dos anos de 1970. Do lado brasileiro, a cidade de Cascavel, distante de mais de $170 \mathrm{~km}$ de Foz do Iguaçu, é sede da Contriguaçu (Cooperativa Central Regional Iguaçu Ltda) que tem como acionistas quatro grandes cooperativas ${ }^{9}$ originárias do Oeste do Paraná. Essa cidade assume importância como centro logístico que controla o terminal ferroviário-câmara frigorífica e o armazém graneleiro que se conectam com o terminal portuário próprio no porto de Paranaguá ${ }^{10}$.

Essas cadeias apresentam elevada densidade técnica e de organização. Foram feitos avanços na logística, principalmente nos aspectos relativos ao armazenamento, à manipulação e ao agenciamento de cargas, ao melhoramento de linhagens e insumos, à automatização da linha de produção, e ao controle de condições sanitárias. Essa densidade técnica, econômica e financeira, foi acompanhada pela expansão do cooperativismo, ampliação de escala da produção e ganho de vantagens competitivas. As cooperativas desenvolveram estratégia de integração vertical a partir da agregação de produtores de pequeno, médio e grande porte, implantação de frigoríficos, pontos de comercialização e logística de armazenamento.

Em certa medida, um tipo de cooperativismo empresarial vertebra a formação dessa região transfronteiriça trinacional. Não se pode negligenciar o fato de que houve uma mudança significativa na escala da produção, marcada pela presença de agentes como BRF, cooperativas como $\mathrm{LAR}^{11}$, FRIMESA ${ }^{12}$ e COPAVEL ${ }^{13}$, do lado brasileiro, e empresas exportadoras de soja no Para-

\footnotetext{
${ }^{9}$ São acionistas da Cooperativa Central Regional Iguaçu Ltda: C. VALE, COOPAVEL, COPACOL e LAR. Esta Cooperativa exerce a função de braço logístico, gerenciamento e transporte em containers.

10 Um outro complexo agroindustrial formado pela expansão da cadeia de proteína animal e vegetal, foi iniciado com a aquisição em 1964 de um frigorífico, e organizado em torno de uma grande empresa, a Sadia, no município de Toledo. ${ }^{11}$ A LAR Cooperativa Agoindustrial, com sede em Medianeira, Paraná, foi fundada em 1964, como COMASIL (Cooperativa Mista Agrícola Sipal Ltda), por 55 agricultores migrantes originários do Rio Grande do Sul e Santa Catarina para ocupar a gleba dos Bispos recém aberta à colonização. Em 1970, tornou-se Cooperativa Agropecuária Três Fronteiras Ltda (COTREFAL). Em 2019 a LAR tem unidades de produção de grãos, de enlatados, frigoríficos, armazenamento em 11 municípios do Oeste do Paraná, no Leste do Paraguai (10 unidades), em Mato Grosso do Sul (14 unidades), e em
} 
guai, como a chinesa COFCO International Paraguay S. A. (15\% do volume exportado pelo país, 827, 3 mil ton exportadas), Cargill, Sodrugestvo Paraguay S. A (empresa russa que exporta 676,7 mil ton, aproximadamente $12 \%$ do volume exportado), além das empresas Vicentin Paraguay S. A (12\%), LDC (6\%), Agrofértil (5\%), Bunge (5\%), Francisco Vierci (4\%), Amaggi (3\%), Trans Agro (3\%), CHS (2\%) e outros que somam $4 \%{ }^{14}$. A expansão da produção de grãos ocupa grandes extensões de terras e pressiona no sentido da concentração fundiária, uso de máquinas e equipamentos de grande porte, bem como o emprego de fertilizantes ${ }^{15}$.

A oferta de serviços no aglomerado urbano está apoiado na infraestrutura viária, que tem nas pontes da Amizade (Foz do Iguaçu-Ciudad del Este, inaugurada em 1965) e da Fraternidade (Foz do Iguaçu-Puerto Iguazu, inaugurada em 1985) as bases que dinamizam e intensificam os fluxos cotidianos, pendulares, e comerciais associados a diferentes cadeias, principalmente aqueles associados à cadeia do turismo, nos segmentos de compras, de jogos em cassinos, de negócios e de aventura. Neste aglomerado, diferenças de salário e de renda e atividades informais coexistem com circuitos formais na mesma cadeia produtiva (ANDRE et al.,), e com a precariedade de serviços de água e esgoto (MAIDANA, 2016). Este aglomerado tem uma posição particular no que diz respeito às redes urbanas específicas de cada país, e ao sistema urbano regional, sem, no entanto, possuir um instituto jurídico próprio, à semelhança, por exemplo, de regiões metropolitanas ou regiões integradas de desenvolvimento. Assim, os espaços das interações cotidianas e os espaços bem integrados à economia internacional pela cadeia de proteína animal e produção de grãos apresentam dinâmica relativamente autônoma, mas interdependente.

A cadeia de produtos madeireiros tem organização em escala industrial. Nessa escala de produção, a cadeia de madeira está presente ao longo da rodovia nacional RN 12, província de Misiones, Argentina, ao longo da qual observou-se: florestas plantadas, pastos e agricultura substituindo a vegetação original dos bosques misoneros ${ }^{16}$; instalação de unidades de produção de papel e celulose; e a presença de quantidade expressiva de unidades de fabricação de produtos em madeira (pranchas, laminados, compensados, aglomerados) com conexão com três polos moveleiros principais:Santa Fé e Buenos Aires, na Argentina, e Santa Maria, RS, Brasil. No caso da celulose, três departamentos concentram a produção: Iguazu, Montecarlo e Libertador General San Martin. Em 2012, o Brasil representou 26\% do total de exportações de celulose produzida na província de Misiones.

O exemplo mais significativo nesse espaço transfronteiriço é a presença da Papelera Alto Paraná, subsidiária da Arauco, da qual o grupo Angelini detém, por meio da COPEC (Companhia de Petróleos de Chile), 99,98\% do capital. Os investimentos da Papelera Arauco englobam a pro-

\footnotetext{
Santa Catarina com uma unidade para produção de sementes. Disponível em: <http://www.lar.ind.br/v4/institucional/index.php\#l historia>. Acesso em 10 set. 2020.

12 Fundada em 1977 por quatro cooperativas e a associação de 6.800 produtores sob a denominação de Cooperativa Central Sudcoop. A industrialização de carne suína iniciou com a aquisição do Frigorífico Medianeira, em 1978. A Sudcoop tinha como filiada a COTREFAL. Disponível em: <https://www. frimesa.com.br/pt/>. Acesso em: 10 set. 2020.

${ }^{13}$ Cooperativa Agroindustrial de Cascavel foi criada em 1970 para concentrar a produção de grãos. Disponível em: <http://www.cotriguacu.com.br/filiadas/coopavel.html>. Acesso em: 10 set. 2020.

14 ADN Paraguayo. Empresa china lidera ranking de las exportadoras de soja. Disponível em: <https://www.adndigital.com.py/empresa-china-lidera-ranking-las-exportadoras-soja/>. Acesso em 30 jan. 2020.

${ }^{15}$ Estudos do Servicio nacional de Calida y Sanidad Vegetal y Semilas indicam o aumento expressivo do uso de glifosato nas áreas com cultivo de soja.

16 "Bosques misioneros" denominação da vegetação original da província de Misiones, com característica de vegetação subtropical úmida.
} 
priedade de 256.000 hectares com florestas naturais, plantadas e reflorestadas, dois viveiros, uma planta de celulose localizada em Puerto Esperanza, duas serrarias, uma fábrica de MDF, além de uma subsidiária, a Leasing Florestal S.A. Trata-se da maior unidade de celulose da Argentina com sérias implicações no que diz respeito à redução das áreas cobertas por vegetação natural, deslocamento de população indígena e de pequenos agricultores, contaminação de água pelo uso de produtos químicos.

As tensões geopolíticas herdadas do passado parecem reavivadas na competição entre Embrapa e INTA. Enquanto na unidade EMBRAPA Florestas os investimentos em P\&D são direcionados para produtos florestais, erva-mate, eucalipto, sistemas silvipastoris ${ }^{17}$, do lado argentino, o Instituto Nacional de Tecnologia Agropecuária (INTA), por meio da INTeA S.A viabiliza a conexão entre o Instituto e os atores da cadeia agroindustrial para transferência de tecnologia, comercialização de inovações, assistência institucional.

Assim, a estrutura da região trinacional em consolidação abrange espaços bem integrados à escala global pela presença das cadeias organizadas em torno de atividades floresto-industriais, da cadeia de proteína animal e vegetal às quais se conectam pequenos núcleos urbanos de apoio à produção; espaços com interações cotidianas fortes e regulares pela presença de grandes aglomerações, cuja dinâmica está associada à cadeia do turismo, à prestação - formal e informal, legal e ilegal - de serviços, e à criação de parques nacionais, fomentando o turismo (PIRES DO RIO; NAME, 2017), e constituindo espaços de preservação da biodiversidade.

Por fim, um espaço de inovação projeta-se no eixo Toledo-Cascavel pela presença de indústria farmacêutica no município de Toledo. O grupo Prati-Donaduzzi ${ }^{18}$, por exemplo, com sede neste município, constitui elo fundamental da cadeia de inovação a partir da produção de medicamentos genéricos, rotas de síntese e desenvolvimento de novos produtos. Atua como empresa âncora de um parque tecnológico por meio de investimentos em rotas de química fina e biotecnologia. Esses espaços são, no contexto regional ${ }^{19}$, organizados como redes de empresas de biotecnologia, fármacos e serviços médicos, e nos quais a proximidade geográfica exerce papel importante nas relações técnicas e na configuração de ambiente institucional.

\section{Considerações Finais}

A formação de regiões transfronteiriças envolve processos e interesses em escalas variadas e articuladas. A comparação efetuada constatou que a demanda internacional por proteína animal e vegetal, por um lado, e interesses geopolíticos e geoeconômicos, por outro, geram similaridades e diferenças no desenvolvimento de cadeias produtivas e na dinâmica econômica resultante da exploração de vantagens comparativas e competitivas. A comparação entre as duas fronteiras trinacionais evidenciou igualmente níveis e densidade de integração das cadeias consideradas, bem como uma defasagem no tempo no processo de formação de regiões transfronteiriças. Confirmouse a assertiva sobre o papel de cadeias produtivas como elemento relevante na formação de regi-

\footnotetext{
${ }^{17}$ Sistemas silvipastoris são definidos como modalidade de uso da terra que combina práticas de manejo do solo como, pecuária e plantio de espécies arbóreas, que inclui o eucalipto.

${ }^{18}$ Entrevista realizada em 30/08/2017 junto à gerência de projetos da Empresa.

${ }^{19}$ Ainda que as conexões desses espaços não se limitem à região.
} 
ões pela conexão e articulação concreta de interesses em escalas variadas (internacional, nacional, regional e local).

Se as bases da conexão entre Peru e Brasil, Bolívia e Brasil, Brasil e Paraguai, estiveram apoiadas em dispositivos próprios às relações internacionais bilaterais (acordos e tratados comerciais e de preferências tarifárias, programas de cooperação técnica e cultural, mecanismos e organismos de financiamento, acordos para a prestação de serviços, etc.), estes não estavam desvinculados de projetos de investimentos em infraestrutura de transporte, como estradas de rodagem, ferrovia, hidrovia ou de infraestrutura energética. Crises econômicas e limitações impostas pela crise da dívida nesses países em momentos distintos dificultaram a implantação dos investimentos idealizados, ou encontraram resistência em movimentos sociais de diferentes matizes. Parte desses projetos foi retomada nos planos de integração sul-americana.

No caso da fronteira trinacional Brasil, Paraguai, Argentina, os portos e terminais fluviais ganham importância face aos gargalos do escoamento da produção agrícola, principalmente, por rodovia e ferrovia, para os portos de Santos e Paranaguá, situados no litoral brasileiro. À escala supranacional, referência para a dinâmica transfronteiriça, associou-se a escala regional/local como nível de análise para as aglomerações urbanas como atores regionais que pressionam por mobilidade espacial intra-urbana. 
ALBUQUERQUE, José Lindomar. Fronteiras e identidades em movimento: Fluxos migratórios e disputas de poder na fronteira Paraguai- Brasil. Cadernos CERU, v. 19, n. 1, p. 49-63, 2008.

ANDRE, A. et al. Dinâmicas urbanas de transfronteirização em Foz do Iguaçu - Brasil, Puerto Iguazu - Argentiana e Ciudad del Este - Paraguai. Políticas de Desenvolvimento Regional e de Produção de Energia, Regulação e a Formação de Regiões Transfronteiriças na Amazônia e no Prata, Relatório de Pesquisa do Projeto, Edital MCTI/CNPq/Universal 14/2014, inédito.

BAYMA, M. et al. Aspectos da cadeia produtiva da castanha-do-brasil no estado do Acre, Brasil. Boletim do Museu Paraense Emilio Goeldi Ciências Naturais, Belém, v. 9, n. 2, p. 471426, maio/ago. $2014 . \quad$ Disponível em: $<$ https://ainfo.cnptia.embrapa.br/digital/bitstream/item/109501/1/Bayma-et-al-2014-AspectosCadeia-prod-Boletim-MPEG.pdf>. Acesso em: 15 set. 2019.

BENEDETTI, E. C. B. A Los Espacios Fronterizos Binacionales del Sur Sudamericano em Perspectiva Comparada. Revista GeoPantanal, n. 15, jul-dez, p. 37-62, 2013.

BENEDETTI, E. C. B. Cooperação internacional e a agenda de desenvolvimento social no Mercosul: novas perspectivas para a integração. 2014. Dissertação (Mestrado em Políticas Públicas, Estratégias e Desenvolvimento) - Universidade Federal do Rio de Janeiro, Rio de Janeiro, 2014.

BENEDETTI, E. C. B. A Espacios fronterizos del sur sudamericano. Estudios Fronterizos, nueva época, v. 15, n. 29, p. 11-47, 2014

BERTRAND, J-P;THÉRY, H. Le marché mondial er l'expansion du "complexe du soja dans les cerrados du Mato Grosso. In: LOMBARD, J; MESCLIER, E; VELUT, S. La Mondialisation coté sud: acteurs et territoires. Paris: IRD Éditions/ENS, 2006.

BÜLHER, Eve Anne. La familia, ¿componente intrínseco de la actividad agropecuaria? El ejemplo de las explotaciones arroceras de Río Grande do Sul (Brasil). Anuario americanista europeo, n. 6-7, p.25-57, 2008-2009. Disponível em: <https://dialnet.unirioja.es/servlet/articulo?codigo=3403090>. Acesso em: 15 set. 2020.

CARDIN, Eric Gustavo. Globalização e desenvolvimento regional na Tríplice Fronteira. Revista Ciências Sociais Unisinos, v. 45, n.2, p. 162-170, 2009.

CARNEIRO FILHO, Camilo P. Processos de Transfronteirização na Bacia do Parta: a Tríplice Fronteira Brasil-Argentina-Paraguai. Tese. Porto Alegre: UFRS/POSGEA, 2013.

CASTRO, Edna. Expansão da fronteira, megaprojetos de infraestrutura e integração sulamericana. Cad. CRH, Salvador, v. 25, n. 64, p. 45-62, Apr., 2012. Disponível em $<$ http://www.scielo.br/scielo.php?script=sci_arttext\&pid=S010349792012000100004\&lng=en\&nrm=iso >. Acesso em: 29 Jan. 2020. 
CAUSARANO, Mabel. Paraguay: Regiones metropolitanas fronterizas. Uma puesta al día. Santiago: CEPAL $2011 . \quad$ Disponível em: <https://www.cepal.org/sites/default/files/events/files/mabel causarano.pdf>. Acesso em: 15 set. 2020.

CEPAL - COMISIÓN ECONÓMICA PARA AMÉRICA LATINA Y EL CARIBE. Población, territorio y desarrollo sostenible. Ecuador: Comité Especial de la Cepal sobre Población y DesarroIlo, 2012

CEPAL - COMISIÓN ECONÓMICA PARA AMÉRICA LATINA Y EL CARIBE. Definición de población urbana y rural utilizadas en los censos de los países latinoamericanos. 2013. Disponível em: <https://www.cepal.org/sites/default/files/def_urbana_rural.pdf>. Acesso em: 15 set. 2020.

DIRECCIÓN GENERAL DE ESTADÍSTICA, ENCUESTAS Y CENSOS. Paraguay: Proyección de la Población Nacional, Áreas Urbana y Rural, por Sexo y Edad, 2000-2025. Revisión 2015. Fernando de la Mora: Secretaría Técnica de Planificación de la Presidencia de la República, $2015 . \quad$ Disponível em: <http://www.dgeec.gov.py/Publicaciones/Biblioteca/proyeccion\%20nacional/Estimacion\%20y \%20proyeccion\%20Nacional.pdf>. Acesso em: 15 set. 2020.

EGLER, Claudio. A. G. A formação da rede de cidades na América do Sul. In: Encontro Nacional da Associação Nacional de Pós-Graduação e Pesquisa em Geografia, 2011, Goiânia. Anais.., Goiânia, 2011.

DÉTRIE et al. Strategor. Politique Génerale de l'Entreprise. Paris: Dunod, 1997.

EGLER, Claudio. A. G Referenciais básicos para uma metodologia de identificação do sistema urbano da América do Sul. In: IPEA (Ed.). Rede urbana e integração produtiva no Brasil e na América do Sul. Brasília: Ipea, 2015. p. 47-90.

FAOSTAT - FOOD AND AGRICULTURE ORGANIZATION CORPORATE STATISTICAL DATABASE. Compare Data. 2015.20 Disnponível em: <http://www.fao.org/faostat/en/\#compare>. Acesso em: 15 set. 2020.

FERRARI, M.; DIAS, L. C. Territorialidades transfronteiriças na zona de fronteira seca internacional Brasil-Argentina. In DIAS, L. C.; FERRARI, M. Territorialidades Humanas e Redes Sociais. Florianópolis: Insular, 2 ed, 2013.

GRIMSON, A. La nación en sus límites: contrabandistas y exiliados en la frontera Argentina-Brasil. Barcelona: Gedisa, 2003.

GUIBERT, M. et al. Le Bassin du Rio de la Plata. Développement local et intégration régionale. Toulouse, França: Presses Universitaires du Mirail, 2009.

GUIBERT, M. Soja sans frontières: vers une spécialisation productive du Bassin du Rio de la Plata. In: GUIBERT et al. Le Bassin du Rio de la Plata. Développement local et intégration régionale. Toulouse, França: Presses Universitaires du Mirail, 2009.

GUIBERT, M.; LIGRONE, P. Transfronteirização. In: BIAGINI, H.; ROIG, A. A. Diccionario del pensamiento alternativo. Buenos Aires, 2006. 
HAESBAERT, Rogerio. Elementos para uma regionalização em mundo global desterritorializado. In: MARTNE G. Le Bassin du Rio de la Plata: intégration régionale et développement local. Toulouse: Presses Universitaires du Mirail, 2009, p. 27-49.

IBGE - INSTITUTO BRASILEIRO DE GEOGRAFIA E ESTATÍ́STICA. Cidades@. Disponível em: $<$ http://cidades.ibge.gov.br>. Acesso em: 15 set. 2020.

IBGE - INSTITUTO BRASILEIRO DE GEOGRAFIA E ESTATÍSTICA. Estimativas da população residente no Brasil e Unidades da Federação com data de referência em $1^{\circ}$ de julho de 2016. Rio de Janeiro: IBGE, 2016. Disponível em: <ftp://ftp.ibge.gov.br/Estimativas de Populacao/Estimativas 2016/estimativa dou 201620 160913.pdf>. Acesso em: 15 set. 2020.

IBGE. Distribuição dos Estabelecimentos Rurais - 2006. Rio de Janeiro: IBGE, 2009. Escala 1:5 000 000. Disponível em: <https://www.ibge.gov.br/geociencias/cartas-e-mapas/sociedade-eeconomia/15961-distribuicao-dos-estabelecimentos-rurais.html?=\&t=acesso-ao-produto>. Acesso em: 15 set. 2020.

IGN - INSTITUTO GEOGRÁFICO NACIONAL. Argentina. Disponível em: <http://www.ign.gob.ar/>. Acesso em: 15 set. 2019.

INE - INSTITUTO NACIONAL DE ESTATístICA. Bolívia. Disponível em: $<$ http://www.ine.gob.bo/>. Acesso em: 15 set. 2019.

KUPFER, David. As cadeias globais de valor e seus mitos. Valor Econômico,. 9 nov. 2015. Disponível em: < https://valor.globo.com/opiniao/coluna/as-cadeias-globais-de-valor-e-seusmitos.ghtml>. Acesso em: 15 set. 2020.

LASTRES, Helena M. M.; CASSIOLATO, José E. Glossário de Arranjos e Sistemas Produtivos e Inovativos Locais. SEBRAE, 2003. Disponível em: <https://www.ets.ufpb.br/pdf/2013/Livros\%20e\%20artigos\%20extras/Gloss\%C3\%A1rio\%20d e\%20Arranjos\%20e\%20Sistemas\%20Produtivos.pdf>. Acesso em: 15 set. 2020.

LIMA, Maria Helena Palmer. Cidade-campo, urbano-rural: uma contribuição ao debate a partir de pequenas cidades em Minas Gerais. Tese - Programa de Pós-Graduação em Geografia/UFRJ, Rio de Janeiro, 2007.

LOMBARD, J.; MESCLIER, E.; VELUT, S. La Mondialisation coté sud: acteurs et territoires. Paris: IRD Éditions/ENS, 2006.

MAIDANA, Fernanda. Preocupaciones y desafíos de la política en tres ciudades de frontera: Puerto Iguazú, Foz do Iguaçu y Ciudad del Este. Revista Campos, v. 17, n. 1 ,p. 99-126, 2016.

MACHADO, Lia O. Limites, Fronteiras e Redes. In: STROHAECKER, T. M. et al. (org.). Fronteiras e Espaço Global,. Porto Alegre, AGB - Porto Alegre, v. 49, p.41-49, 1998.

MACHADO, Lia O. Limites e Fronteiras. Da alta diplomacia aos circuitos da ilegalidade. Revista Território, v. 8, p. 9-29, 2000.

MACHADO, Lia. O. Estado, territorialidade, redes: Cidades Gêmeas na zona de fronteira sulamericana. In: SILVEIRA, M L (org.). Continente em Chamas: Globalização e território na América Latina. Rio de Janeiro: Civilização Brasileira, 2005. 
MACHADO, Lia O.; RIBEIRO, Letícia P.; MONTEIRO, Licio C. R. Geopolítica fragmentada: interações transfronteiriças entre o Acre (Brasil), o Peru e a Bolívia. Cuadernos de Geografia/Revista Colombiana de Geografia, v. 23, n. 2, jul-dez, 2014, p. 15-30, 2014.

MACAGNO, L.; MONTENEGRO, S.; BÉLIVEAU, V. (orgs.). A Tríplice Fronteira: Espaços e Dinâmicas. Curitiba: Editora UFPR, 2011

MOURA, Rosa; PÊGO, Bolivar. Aglomerações urbanas no Brasil e na América do Sul: trajetórias e novas configurações. Rio de Janeiro: IPEA, Texto para Discussão, n. 2203, 2016.

NEVES, A. J. et al. Segurança pública nas fronteiras, diagnóstico socioeconômico e demográfico: Estratégia Nacional de Segurança Publica. Brasília: Ministério da Justiça e Cidadania, Secretaria Nacional de Segurança Pública, 2016.

PERKMANN, M.; SUM, N.-L (orgs.). Globalization, Regionalization and Cross-Border Regions: Scales, Discourses and Governance. New York: Palgrave Macmillan, 2002.

PINHEIRO-MACHADO, Rosana Made in Chine: (in)formalidade, pirataria e redes sociais na rota China-Paraguai-Brasil. São Paulo: HUCITEC, 340p., 2011.

PIRES do RIO, Gisela. A. A espacialidade da economia: superfícies, fluxos. In: Castro, Gomes e Corrêa (Orgs) Olhares Geógraficos. Rio de Janeiro, Bertrand Brasil, pp. 155-188, 2012.

PIRES DO RIO, Gisela A.; NAME, Leonardo P. M. Patrimonialización y gestión del território em la Triple Frontera de Brasil, Argentina y Paraguay: continuidades y desafios del Parque Iguazú. Revista de Geografía Norte Grande, v. 67, p. 167-182, 2017.

RIBEIRO, Leticia. P. Interações espaciais na Fronteira Brasil-Paraguai: as cidades gêmeas Foz do Iguaçu e Ciudad del Este. Dissertação - Programa de Pós-Graduação em Geografia - UFRJ, Rio de Janeiro, 2001.

RABOSSI, Fernando. En las calles de Ciudad del Este: Una etnografia del comercio de frontera Asunción: Centro de Estudios Antropológicos de la Universidad Católica, 2003.

RABOSSI, Fernando. Made in Paraguai. Notas sobre la producción de ciudad Del Leste. Revista Electrónica del IDAES, Buenos Aires, v. 6, 2010. Disponível em $<$ http://www.idaes.edu.ar/papelesdetrabajo/paginas/Documentos/7\%20Rabossi.pdf>. Acesso em: 15 nov. 2019.

RENOLDI, Brígida. Fronteras que caminan: relaciones de movilidad en un límite trinacional. Revista Trasporte y Territorio, v. 9, p. 123-140, 2013.

REOLON, Cleverson. A aglomeração urbana internacional de Foz do Iguaçu/Brasil:uma aproximação através da análise da migração pendular. AGIR - Revista Interdisciplinar de Ciências Sociais e Humanas, v. 1, n. 6, p. 46-60, 2013.

SCHWEITER, A. Dinamicas espaciales y territórios de la integraciónen la fronteras del Iguazú. In: GUIBERT et al. Le Bassin du Rio de la Plata. Développement local et intégration régionale. Toulouse, França: Presses Universitaires du Mirail, 2009.

SILVA, Luis Paulo B da. A geografia das cidades gêmeas de Corumbá (Brasil) e Porto Suárez (Bolívia): interações espaciais na zona de fronteira Brasil - Bolívia. Dissertação - Programa 
de Pós Graduação em Geografia, Universidade Federal do Rio de Janeiro, Rio de Janeiro, 2012.

SILVA, Luis Paulo B da. Hidropolítica sul-americana e a Bacia do Prata: o lugar das sub-bacias em zonas de fronteira internacional. Tese. Rio de Janeiro: PPGG/UFRJ, 2017.

SOHN, C. Modelling Cross-Border Integration: The Role of Borders as a Resource. Geopolitics, v. 19, p. 587-608, 2014.

STEIMAN, R.; MACHADO, L. O. Limites e Fronteiras Internacionais: uma discussão históricogeográfica. In: Terra Limitanea. Atlas da Fronteira Continental do Brasil. Rio de Janeiro: Grupo Retis, 2002. Disponível em: <http://www.retis.igeo.ufri.br/producao/artigos/limites-efronteiras-internacionais-uma-discuss\%C3\%A3o-hist\%C3\%B3ricogeogr\%C3\%A1fica/\#.WG Ne1UrKM8\#ixzz4V0BEOfel>. Acesso em: 15 set. 2020.

VASQUEZ, F (2009): "Frente pioneiro del ganado bovino em las márgenes del Imercosur y emergência territorial en la frontera paraguayo-brasileña". In: GUIBERT, Martine; et al. Le Bassin du Rio de la Plata : intégration régionale et développement local, Presses Universitaires du Mirail/ Collection Hespérides Amérique, Toulouse. 